\title{
Flavourings significantly affect inhalation toxicity of aerosol generated from electronic nicotine delivery systems (ENDS)
}

\author{
Noel J Leigh, ${ }^{1}$ Ralph I Lawton, ${ }^{1}$ Pamela A Hershberger, ${ }^{2}$ Maciej L Goniewicz'
}

- Additional material is published online only. To view please visit the journal online (http://dx.doi.org/10.1136/ tobaccocontrol-2016-053205).

${ }^{1}$ Department of Health Behavior, Roswell Park Cancer Institute, Buffalo, New York, USA

${ }^{2}$ Department of Pharmacology and Therapeutics, Roswell Park Cancer Institute, Buffalo, New York, USA

\section{Correspondence to} Dr Maciej L Goniewicz, Division of Cancer Prevention and Population Sciences, Department of Health Behavior, Roswell Park Cancer Institute, Elm and Carlton Streets, Carlton House A320, Buffalo, NY 14263, USA; maciej.goniewicz@roswellpark. org

Received 27 May 2016 Revised 15 August 2016 Accepted 16 August 2016

Published Online First 15 September 2016

\section{ABSTRACT}

Background E-cigarettes or electronic nicotine delivery systems (ENDS) are designed to deliver nicotinecontaining aerosol via inhalation. Little is known about the health effects of flavoured ENDS aerosol when inhaled.

Methods Aerosol from ENDS was generated using a smoking machine. Various types of ENDS devices or a tank system prefilled with liquids of different flavours, nicotine carrier, variable nicotine concentrations and with modified battery output voltage were tested. A convenience sample of commercial fluids with flavour names of tobacco, piña colada, menthol, coffee and strawberry were used. Flavouring chemicals were identified using gas chromatography/mass spectrometry. H292 human bronchial epithelial cells were directly exposed to 55 puffs of freshly generated ENDS aerosol, tobacco smoke or air (controls) using an air-liquid interface system and the Health Canada intense smoking protocol. The following in vitro toxicological effects were assessed: (1) cell viability, (2) metabolic activity and (3) release of inflammatory mediators (cytokines).

Results Exposure to ENDS aerosol resulted in decreased metabolic activity and cell viability and increased release of interleukin (IL)-1 $1 \beta$, IL-6, IL-10, CXCL1, CXCL2 and CXCL10 compared to air controls. Cell viability and metabolic activity were more adversely affected by conventional cigarettes than most tested ENDS products. Product type, battery output voltage and flavours significantly affected toxicity of ENDS aerosol, with a strawberry-flavoured product being the most cytotoxic.

Conclusions Our data suggest that characteristics of ENDS products, including flavours, may induce inhalation toxicity. Therefore, ENDS users should use the products with caution until more comprehensive studies are performed.

\section{BACKGROUND}

Electronic nicotine delivery systems (ENDS) are battery-powered, nicotine-delivery devices marketed as safer substitutes for traditional cigarettes. ${ }^{1}$ Although ENDS seem to be a promising harm reduction tool for smokers, findings indicate that use of these products can result in repeated inhalation of respiratory irritants and toxicants, with long-term users risking regular exposure. Chemical studies demonstrate that ENDS aerosol contains low levels of toxicants and carcinogens, ${ }^{2}{ }^{3}$ though generally fewer than in conventional tobacco cigarettes. Toxicological and clinical studies on health effects of ENDS are lagging behind the rapid growth in their use by the public. ${ }^{4}$ This lack of studies also hampers regulatory action. ${ }^{56}$

The popular flavours among ENDS users include traditional flavours such as tobacco or menthol and non-traditional flavours such as a fruit (eg, cherry, berry, apple), sweet (eg, chocolate, vanilla, desserts, candies) or a beverage (eg, coffee, alcoholic drinks, soda). ${ }^{78}$ Hutzler $e t a l^{9}$ analysed 28 ENDS liquids by gas chromatography/mass spectrometry (GC/MS) and identified 141 different flavouring chemicals among them. Although many of the flavouring chemicals used in ENDS liquids have been certified as 'generally recognised as safe' for ingestion by the Flavours Extracts Manufacturers Association, little is known about their effects when inhaled or heated in ENDS products. ${ }^{10}$ Farsalinos et al ${ }^{11}$ evaluated sweet-flavoured e-liquids for the presence of diacetyl and acetyl propionyl, which are chemicals approved for food use but are associated with respiratory disease when inhaled. Both compounds were detected in a large proportion of products, with many of them exposing users to higher than safe levels. Kosmider $e t a l^{3}$ examined benzaldehyde levels in aerosols generated from a wide range of flavoured nicotine solutions and established that users of flavoured ENDS are exposed to significant amounts of this respiratory irritant. Moreover, users of cherry-flavoured products may inhale significantly higher doses of benzaldehyde compared to users of other flavoured products. ${ }^{3}$

A recent report by Barrington-Trimis et al ${ }^{12}$ outlined the need for research on flavour additives used in ENDS, noting the lack of safety data on long-term health effects from inhaling flavouring chemicals. There is a need to develop toxicological test models, which characterise the toxic response and cellular interaction between constituents of inhaled ENDS aerosol, including flavours, and the respiratory system. The extent to which variable product features, including flavourings, impact cellular responses is currently not well defined.

There have been generally few toxicological studies that investigated the cellular effects of exposure to ENDS aerosol. Those that have been performed used a variety of cell types, including cardiomyoblasts and the lung epithelial cell line, H292. ${ }^{11} 13$ Published studies seem to indicate either no or very little toxicity of ENDS, ${ }^{14}$ although other studies suggest potential oxidative stress and inflammatory responses. ${ }^{15-19}$ However, those studies only used a low-voltage refillable tank system (eGo) or a single brand of disposable ecigarette, neither of which contained various flavours. The potential effect that flavouring
Lawton RI, Hershberger PA et al. Tob Control 2016;25: ii81-ii87. 
compounds may have on the respiratory cells of ENDS users is unclear. Behar $e t a l^{20}$ studied flavouring compounds in ENDS solutions and found differences in toxicity among flavours. The same group of researchers found that the cinnamon flavourings in refill fluids are linked to cytotoxicity, which could adversely affect ENDS users. ${ }^{20}$

Inhalation of complex mixtures such as flavoured ENDS aerosols can cause a wide range of adverse health effects, ranging from simple irritation to systemic diseases. ${ }^{21}$ Traditionally, inhalation toxicity has been performed on test animals to identify various end points, including the lethal concentration of airborne materials or maximum tolerable concentration. ${ }^{22}$ In vitro studies in which a solution of the aerosol ingredients is applied in the medium overlay do not model an inhalation exposure. They also may not be suitable for studying, for example, the effects of some poorly soluble flavouring compounds, such as limonene. More recently, novel in vitro methods have been developed that allow the direct exposure of airborne material to cultured human target cells on permeable porous membranes at the air-liquid interface (ALI). In ALI exposure systems, the cells are provided with nutrients from the basal side of the membrane while the apical side, with the cultivated cells, is in direct contact with the test aerosol. The effects of ENDS aerosols on respiratory cells cultured at the ALI can be used to study cell injury or activation and the release of bioactive mediators including cytokines. Therefore, in vitro studies using an ALI model open up new ways to test ENDS toxicity. ${ }^{23}$ We are aware of only one study published to date that used the ALI method to study ENDS toxicity. ${ }^{13}$ However, that study focused on proinflammatory effects of two ENDS, as measured by secretion of two inflammatory cytokines (interleukin (IL)-6 and IL-8), rather than cytotoxicity or metabolic activity. In our study, the physiologically relevant ALI system was used to individually and systematically evaluate in vitro effects of many of the variables related to ENDS products, including several of the most popular flavours. By testing different types and brands of ENDS products, along with product features on cell viability, cell metabolic activity and inflammatory cytokine production in an ALI system, this study hopes to establish the impact of various product characteristics on potential inhalation toxicity of ENDS products.

\section{MATERIALS AND METHODS}

\section{ENDS products and reference cigarettes}

ENDS devices and refill solutions were selected for study from a vast and rapidly changing array of products. Six types of ENDS were purchased from gas stations, convenience stores, online retailers and local 'vape' shops in Buffalo, New York, USA; Daly City, California, USA and online (table 1). Refill solutions for tank systems in five flavours tobacco, piña colada, menthol, coffee, and strawberry were also purchased from a local 'vape' shop in Buffalo, New York, USA (table 1). Tobacco reference cigarettes 3R4F were obtained from the University of Kentucky.

In a pilot experiment, cells were exposed to six different ENDS products including a disposable e-cigarette, rechargeable e-cigarette, tank-type eGO device, a personal vaporiser, an ePipe and an eCigar (table 1). In all subsequent experiments, we used one type of ENDS device, specifically an eGo tank system (Vision Spinner), with battery output voltage fixed at $3.3 \mathrm{~V}$. However, we systematically and individually modified product features by refilling the device with various carriers, with solutions of variable nicotine concentration or solutions with different flavours. To compare the cellular toxicity of carriers, e-liquids containing $24 \mathrm{mg} / \mathrm{mL}$ of nicotine and without flavour were prepared in a laboratory using USP-grade ingredients (US Pharmacopeia) in propylene glycol (PG)-only, vegetable glycerin (VG)-only or a 50/50 mixture of PG/VG, along with 5\% distilled water. To study the effects of nicotine concentration on bronchial epithelial cells, an eGo tank system was set to $3.3 \mathrm{~V}$ and prefilled with PG-only unflavoured solution that contained 0,6 , 12,18 or $24 \mathrm{mg} / \mathrm{mL}$ of nicotine. Nicotine concentrations in all tested products were determined using gas chromatography with a nitrogen-phosphorous detector (GC-NPD), as described previously. ${ }^{24} 25$ To measure the effects of ENDS voltage on cellular toxicity, aerosols were generated from an eGo tank system filled with PG-only solution containing tobacco flavour and $24 \mathrm{mg} / \mathrm{mL}$ of nicotine that was set to $3.3,4.0$ or $4.8 \mathrm{~V}$.

To study the effects of flavours, an eGo tank system set to $3.3 \mathrm{~V}$ was prefilled with PG-only liquid containing the same nicotine concentration $(24 \mathrm{mg} / \mathrm{mL}$; labelled) but with various flavours (table 2). Flavouring chemicals were identified in each liquid using a GC/MS method, as described in online supplementary materials. An untargeted analyte list was generated and included the 11 compounds listed in table 2. Tobacco, piña colada, menthol, coffee and strawberry had the following GC-NPD determined nicotine concentrations: 23.0, 22.5, 22.0, 21.8 and $22.5 \mathrm{mg} / \mathrm{mL}$, respectively (table 2). No GC-NPD analysis was performed on aerosols generated from the fluids.

\section{Generation of ENDS aerosol}

Aerosol from ENDS products, as well as tobacco smoke, was generated using a Borgwaldt LX-1 (Richmond, Virginia, USA) single-port piston-operated smoking machine. The puffing protocol was based on the Health Canada Intense method, ${ }^{26}$ using the following conditions: $3 \mathrm{~s}$ puff duration, every $30 \mathrm{~s}$, with a $55 \mathrm{~mL}$ puff volume. The puffing protocol was implemented continuously for $30 \mathrm{~min}$, resulting in a total of 55 puffs. A period of $30 \mathrm{~min}$ was used as this was the minimum exposure

Table 1 Product characteristics of ENDS tested in this study

\begin{tabular}{lllllllll}
\hline & Brand & Purchase site & $\begin{array}{l}\text { Battery } \\
\text { output } \\
\text { voltage (V) }\end{array}$ & $\begin{array}{l}\text { Resistance } \\
\text { of heating } \\
\text { element (Ohms) }\end{array}$ & $\begin{array}{l}\text { Device } \\
\text { power (W) }\end{array}$ & $\begin{array}{l}\text { Nicotine } \\
\text { carrier }\end{array}$ & $\begin{array}{l}\text { Labelled nicotine } \\
\text { concentration } \\
\text { (mg/mL) }\end{array}$ & $\begin{array}{l}\text { Determined nicotine } \\
\text { concentration } \\
\text { (mg/mL) }\end{array}$ \\
\hline Disposable & Blu & Buffalo, New York, USA & Unknown & Unknown & Unknown & Unknown & $\sim 24$ & 12.3 \\
Rechargeable & Blu & Buffalo, New York, USA & 3.4 & 3.2 & 3.6 & Unknown & $\sim 16$ & 12.9 \\
eGO & Vision Spinner & Daly City, California, USA & 3.3 & 2.9 & 3.8 & PG-only & 24 & 24.2 \\
Vaporiser & KBOX & Online & 4.5 & 1.9 & 10.7 & PG-only & 24 & 24.2 \\
ePipe & Kamry & Online & 4.2 & 2.8 & 6.3 & PG-only & 24 & 24.2 \\
eCigar & Veppo & Online & Unknown & Unknown & Unknown & Unknown High & 11.2 \\
\hline
\end{tabular}

ENDS, electronic nicotine delivery systems; PG, propylene glycol. 
Table 2 Nicotine concentration and major flavouring chemicals identified in flavoured ENDS refill solutions used in this study

\begin{tabular}{|c|c|c|c|c|c|}
\hline Flavour brand name & $\begin{array}{l}\text { Labelled nicotine } \\
\text { concentration }(\mathrm{mg} / \mathrm{mL})\end{array}$ & $\begin{array}{l}\text { Determined nicotine } \\
\text { concentration }(\mathrm{mg} / \mathrm{mL})\end{array}$ & Identified flavouring chemicals & CAS Registry Number & Class \\
\hline Tobacco & 24 & 23.0 & $\begin{array}{l}\text { 3-Methylcyclopentane-1,2-dione } \\
\text { (E)- } \beta \text {-damascone }\end{array}$ & $\begin{array}{l}765-70-8 \\
23726-91-2\end{array}$ & $\begin{array}{l}\text { Diketone } \\
\text { Ketone }\end{array}$ \\
\hline Piña Colada & 24 & 22.5 & $\begin{array}{l}\text { Allyl-cyclohexylpropanoate } \\
\text { Methyl 3-hydroxyhexanoate }\end{array}$ & $\begin{array}{l}2705-87-5 \\
21188-58-9\end{array}$ & $\begin{array}{l}\text { Ester } \\
\text { Ester }\end{array}$ \\
\hline Menthol & 24 & 22.0 & $\begin{array}{l}\text { Menthol } \\
\text { Limonene } \\
\text { Carvone }\end{array}$ & $\begin{array}{l}1490-04-6 \\
138-86-3 \\
99-49-0\end{array}$ & $\begin{array}{l}\text { Alcohol } \\
\text { Monoterpene } \\
\text { Terpenoid }\end{array}$ \\
\hline Coffee & 24 & 21.8 & 5-Methyl-2-phenylhex-2-enal (Cocal) & $4927-36-0$ & Aldehyde \\
\hline Strawberry & 24 & 22.5 & $\begin{array}{l}\text { Benzyl alcohol } \\
\gamma \text {-Decalactone } \\
\text { Methyl cinnamate }\end{array}$ & $\begin{array}{l}100-51-6 \\
706-14-9 \\
1754-62-7\end{array}$ & $\begin{array}{l}\text { Alcohol } \\
\text { Cyclic ester } \\
\text { Ester }\end{array}$ \\
\hline
\end{tabular}

time examined in which we saw significant differences between ENDS aerosol and the air control (data not shown). Air exposures (control) were run during each experiment, and five $3 \mathrm{R} 4 \mathrm{~F}$ reference tobacco cigarettes were smoked for comparison using the same method as for the ENDS products. In pilot studies, cells were exposed to air by two different methods: either we used a 12 psi constant supply of air for 30 min or we drew air over the cells for 55 puffs (for a total of $30 \mathrm{~min}$ ) using the smoking machine. No significant differences were found between methodologies. Therefore, we employed the smoking machine method to generate air controls for each experiment.

\section{Cell exposure conditions}

The NCI-H292 cell line (American Type Culture Collection) was used for all experiments. A detailed description of the maintenance and propagation of $\mathrm{H} 292$ cells is provided in online supplementary materials. This study used an ALI system that enables direct exposure of cells to ENDS aerosol (see online supplementary figure S1). Cells were grown on the apical side of $0.4 \mu \mathrm{m}$ permeable supports (PS) under standard conditions for cell maintenance (described in online supplementary materials). Immediately prior to exposure, the media were aspirated from the apical side of the PS, and cell-containing inserts $(n=3)$ were placed in the ALI chamber. While the cells were directly exposed to ENDS aerosol, fresh media were cycled over the basal side of the PS at a flow rate of $25 \mathrm{~mL} / \mathrm{min}$. The ALI chamber was cleaned with methanol and distilled water between exposures.

\section{Toxicity assays}

Metabolic activity of exposed cells was measured by neutral red uptake assay. Cell viability was measured by trypan blue assay. Cytokine release was measured as an indicator of cell inflammatory response. Seven cytokines (IL-1 $\beta$, IL-6, IL-10, CXCL1, CXCL2, CXCL5 and CXCL10) were measured using commercially available enzyme-linked immunosorbent assay kits. For all assays, we followed protocols provided by the manufacturer. Detailed descriptions of each assay are provided in online supplementary materials. Note that CXCL5 levels measured were below the limit of quantitation for each tested condition. Thus, CXCL5 results are not presented.

\section{Statistical analysis}

Statistical analysis was performed using Prism V.6.07 (GraphPad). Kruskal-Wallis non-parametric tests were performed for each study outcome to compare (1) the mean rank of ENDS products versus air controls, (2) the mean rank of ENDS products versus reference cigarettes and (3) the mean rank of every ENDS product to other ENDS products excluding the air and reference cigarette controls. All experiments were performed at least in duplicate, with each outcome measured three times per experiment.

\section{RESULTS}

Aerosol generated from various types of ENDS products (disposable e-cigarette, rechargeable e-cigarette, eGo tank system, personal vaporiser, ePipe and eCigar) differed significantly in their toxicity to bronchial epithelial cells (table 3A,B and online supplementary table S1). Metabolic activity and viability of H292 cells significantly decreased $(\mathrm{p}<0.05)$ after exposure to aerosols from the eGo tank system, personal vaporiser and ePipe as compared to air control (table 3A, B). A significant decrease in metabolic activity, but not cell viability, was observed between the air control and the blu rechargeable e-cigarette. Notably, some ENDS products tested in the study including the eGo tank system, personal vaporiser and ePipe did not differ significantly from tobacco cigarettes in their effect on metabolic activity or cell viability. However, the disposable e-cigarette, rechargeable ecigarette and eCigar products were significantly less toxic than tobacco cigarettes (table 3A, B). When examining cytokine release on exposure of $\mathrm{H} 292$ cells to ENDS aerosol, we found a significant increase in IL-1 $\beta$, IL- 6 and CXCL1 for the rechargeable e-cigarette, as compared either to the air control or to the reference tobacco cigarette. IL-6, IL10, CXCL1 and CXCL2 release were significantly different between the personal vaporiser and ePipe compared to air, as well as between the ePipe and the reference cigarette (table 3A, B). Not all ENDS products were equivalent with regard to cytokine release. For example, the eGo product did not mediate a change in any of the tested cytokines (table 3A, B and online supplementary table S1).

The above-described pilot experiments confirmed our hypothesis that various ENDS products differ with regard to their cellular toxicity and cause different inflammatory reactions in cells directly exposed to aerosols. However, owing to diversity of the products, we could not attribute toxic effects to a specific feature of each product. We therefore undertook a systematic study to determine how individual product features including flavours, nicotine carrier, nicotine concentration and battery output voltage contribute to cellular toxicity and inflammatory responses in $\mathrm{H} 292$ cells.

\section{Effect of flavours on ENDS aerosol toxicity}

By exposing H292 cells to aerosols generated from the same device (eGo tank system with battery voltage set to $3.3 \mathrm{~V}$ and 
Table 3 Changes in cell viability and metabolic activity and levels of inflammatory mediators released from H292 bronchial epithelial cells exposed directly to 55 puffs of ENDS aerosol, tobacco cigarette smoke or air (controls)

\begin{tabular}{|c|c|c|c|c|c|c|c|c|}
\hline & \multirow[b]{2}{*}{ Viability (\%) } & \multirow{2}{*}{$\begin{array}{l}\text { Metabolic } \\
\text { activity (\%) }\end{array}$} & \multicolumn{6}{|c|}{ (pg/mL $\times 10^{-7}$ cells) } \\
\hline & & & IL-1及 & IL-6 & IL-10 & CXCL1 & CXCL2 & CXCL10 \\
\hline \multicolumn{9}{|c|}{ (A) Control and reference product } \\
\hline Air (control) & $78.6 \pm 2.7^{*}$ & (Reference) $^{*}$ & $12.1 \pm 2.4^{*}$ & $10.3 \pm 0.5^{*}$ & $14.5 \pm 7.0^{*}$ & $16.4 \pm 6.1^{*}$ & $17.0 \pm 6.2^{*}$ & $28.3 \pm 1.6^{*}$ \\
\hline Tobacco cigarette & $3.6 \pm 2.8 \dagger$ & $32.7 \pm 1.8 \dagger$ & $4.0 \pm .0 .1 \dagger$ & $2.1 \pm 0.3 \dagger$ & $6.7 \pm 0.1 \dagger$ & $4.8 \pm 0.4 \dagger$ & $5.2 \pm 0.1 \dagger$ & $10.6 \pm 0.3+$ \\
\hline \multicolumn{9}{|l|}{ (B) ENDS product type } \\
\hline Disposable & $67.2 \pm 4.5^{*}$ & $82.3 \pm 4.8^{*}$ & $22.2 \pm 4.9$ & $57.7 \pm 52.3 \dagger$ & $12.8 \pm 1.2$ & $18.4 \pm 7.0$ & $20.9 \pm 8.4$ & $23.7 \pm 15.2$ \\
\hline Rechargable & $61.1 \pm 25.6^{*}$ & $64.6 \pm 4.6 \dagger^{*}$ & $88.3 \pm 1.8 t^{*}$ & $106.6 \pm 27.0 \dagger^{*}$ & $46.6 \pm 42.4$ & $67.0 \pm 17.5 t^{*}$ & $55.6 \pm 29.1$ & $111.0 \pm 118.9$ \\
\hline eGo & $17.9 \pm 6.6 \dagger$ & $45.1 \pm 2.0 \dagger$ & $31.3 \pm 0.9$ & $23.4 \pm 5.3$ & $24.5 \pm 7.6$ & $22.4 \pm 2.0$ & $26.6 \pm 3.5$ & $47.6 \pm 34.3$ \\
\hline Vaporiser & $25.6 \pm 7.2 \dagger$ & $61.4 \pm 5.1 \dagger$ & $64.9 \pm 1.9$ & $27.6 \pm 6.5 \dagger$ & $54.8 \pm 13.8 t^{*}$ & $48.5 \pm 1.8 \dagger$ & $59.7 \pm 11.4 \dagger$ & $99.7 \pm 65.3$ \\
\hline ePipe & $32.17 \pm 7.1 \dagger$ & $50.1 \pm 2.4 \dagger$ & $82.5 \pm 0.8$ & $66.7 \pm 26.3 \dagger^{*}$ & $55.7 \pm 12.3 \dagger^{*}$ & $63.6 \pm 8.8 t^{*}$ & $68.5 \pm 4.5 t^{*}$ & $112.6 \pm 80.7$ \\
\hline eCigar & $80.1 \pm 11.1^{*}$ & $95.9 \pm 5.0^{*}$ & $13.0 \pm 0.9$ & $67.1 \pm 63.0 \dagger$ & $12.1 \pm 0.2$ & $11.2 \pm 0.1$ & $11.6 \pm 0.4$ & $37.6 \pm 2.8$ \\
\hline \multicolumn{9}{|l|}{ (C) Nicotine carrier } \\
\hline PG-only & $50.7 \pm 21.4 \dagger^{*}$ & $56.2 \pm 1.8^{*}$ & $75.2 \pm 5.3 \dagger$ & $21.3 \pm 4.6 t^{*}$ & $44.5 \pm 25.6 \dagger$ & $40.6 \pm 19.0$ & $47.1 \pm 11.6 \dagger^{*}$ & $105.9 \pm 97.2$ \\
\hline PG:VG (50/50) & $49.7 \pm 5.8 t^{*}$ & $39.4 \pm 5.8 t^{*}$ & $57.8 \pm 25.2$ & $16.9 \pm 6.2 \dagger$ & $41.1 \pm 14.1 \dagger$ & $32.4 \pm 3.1$ & $41.7 \pm 10.2$ & $67.00 \pm 45.1$ \\
\hline VG-only & $45.5 \pm 11.9 \dagger^{*}$ & $42.0 \pm 1.7 \dagger^{*}$ & $31.9 \pm 0.1$ & $15.5 \pm 1.3$ & $42.3 \pm 14.7 \dagger$ & $38.1 \pm 13.1$ & $37.1 \pm 11.3$ & $65.0 \pm 22.0$ \\
\hline \multicolumn{9}{|c|}{ (D) Nicotine concentration in ENDS liquid $(\mathrm{mg} / \mathrm{mL})$} \\
\hline 0 & $75.7 \pm 13.1$ & $92.3 \pm 4.9^{*}$ & $2.2 \pm 0.9$ & $10.8 \pm 1.5$ & $2.1 \pm 0.3$ & $5.3 \pm 1.7$ & $4.8 \pm 0.8$ & $3.8 \pm 2.4$ \\
\hline 6 & $87.3 \pm 5.9^{*}$ & $81.7 \pm 7.1$ & $2.1 \pm 0.2$ & $10.6 \pm 2.2$ & $2.9 \pm 2.0$ & $3.2 \pm 0.9$ & $3.2 \pm 0.5 t$ & $3.6 \pm 2.2$ \\
\hline 12 & $78.7 \pm 16.5$ & $91.9 \pm 2.6^{*}$ & $1.8 \pm 0.1$ & $19.7 \pm 2.2$ & $2.9 \pm 2.0$ & $3.5 \pm 1.1$ & $3.6 \pm 0.8$ & $3.0 \pm 1.8$ \\
\hline 18 & $91.6 \pm 3.9^{*}$ & $92.2 \pm 7.0^{*}$ & $1.8 \pm 0.1 \dagger^{*}$ & $14.6 \pm 7.1$ & $2.9 \pm 1.7$ & $2.8 \pm 1.0 \dagger$ & $2.9 \pm 0.6 t^{*}$ & $3.1 \pm 2.0$ \\
\hline 24 & $89.7 \pm 7.7^{*}$ & $89.3 \pm 8.6^{*}$ & $2.5 \pm 0.1$ & $21.9 \pm 5.0 t^{*}$ & $2.3 \pm 0.3$ & $4.2 \pm 1.2$ & $5.0 \pm 0.5$ & $4.3 \pm 2.7$ \\
\hline \multicolumn{9}{|c|}{ (E) ENDS battery output voltage (V) } \\
\hline 3.3 & $63.4 \pm 4.4^{*}$ & $78.1 \pm 1.4^{*}$ & $31.3 \pm 0.9$ & $23.4 \pm 5.3 \dagger$ & $24.5 \pm 7.6$ & $22.4 \pm 2.0$ & $26.6 \pm 3.5$ & $47.6 \pm 34.3$ \\
\hline 4.0 & $42.3 \pm 4.3 t^{*}$ & $55.5 \pm 1.3 \dagger$ & $39.6 \pm 0.9$ & $13.6 \pm 1.3$ & $43.4 \pm 23.4$ & $29.0 \pm 1.3 \dagger$ & $30.4 \pm 1.1$ & $64.0 \pm 42.8$ \\
\hline 4.8 & $11.7 \pm 5.9 \dagger$ & $46.2 \pm 4.7 \dagger$ & $17.5 \pm 0.1 \dagger^{*}$ & $74.9 \pm 19.6 t^{*}$ & $218.3 \pm 8.2 \dagger^{*}$ & $180.5 \pm 51.4 \dagger^{*}$ & $187.3 \pm 63.0 \dagger^{*}$ & $337.5 \pm 139.2 \dagger^{*}$ \\
\hline \multicolumn{9}{|c|}{ (F) Flavours in ENDS liquid } \\
\hline Tobacco & $63.3 \pm 4.4^{*}$ & $78.1 \pm 1.4^{*}$ & $31.3 \pm 0.9$ & $23.4 \pm 5.3 t^{*}$ & $24.5 \pm 7.6$ & $22.4 \pm 2.0$ & $26.6 \pm 3.5$ & $47.6 \pm 34.3$ \\
\hline Piña Colada & $64.0 \pm 7.8^{*}$ & $63.8 \pm 2.7 t^{*}$ & $25.5 \pm 0.3$ & $11.3 \pm 5.0$ & $26.7 \pm 3.8$ & $27.0 \pm 4.5$ & $27.7 \pm 5.7$ & $48.7 \pm 22.4$ \\
\hline Menthol & $57.2 \pm 10.4 \dagger^{*}$ & $48.5 \pm 5.6 \dagger$ & $16.4 \pm 0.1$ & $14.3 \pm 6.6$ & $35.5 \pm 30.6$ & $21.7 \pm 2.3$ & $26.1 \pm 2.2$ & $34.4 \pm 13.3$ \\
\hline Coffee & $44.3 \pm 15.5 \dagger^{*}$ & $55.8 \pm 2.1 \dagger^{*}$ & $78.1 \pm 3.3$ & $40.7 \pm 9.9 t^{*}$ & $59.8 \pm 27.4$ & $52.7 \pm 18.0 \dagger^{*}$ & $56.0 \pm 14.1 \dagger^{*}$ & $124.3 \pm 103.0$ \\
\hline Strawberry & $12.2 \pm 4.6 \dagger$ & $46.2 \pm 1.9 \dagger$ & $135 \pm 2.8 t^{*}$ & $15.2 \pm 12.8$ & $125.0 \pm 11.3 \dagger^{*}$ & $117.5 \pm 14.8 \dagger^{*}$ & $127.3 \pm 22.4 \dagger^{*}$ & $226.8 \pm 121.0 \dagger^{*}$ \\
\hline \multicolumn{9}{|c|}{$\begin{array}{l}\text { Statistically significant values are shown in bold. } \\
\text { Mean values for cytotoxicity and cytokine assays. Values are mean } \pm \text { SEM. } \\
\text { *Significant difference as compared to tobacco cigarettes ( } p<0.05 \text {; Kruskal-Wallis test). } \\
\text { †Significant difference as compared to air controls ( } p<0.05 \text {; Kruskal-Wallis test). } \\
\text { ENDS, electronic nicotine delivery systems; IL, interleukin; PG, propylene glycol; VG, vegetable glycerin. }\end{array}$} \\
\hline
\end{tabular}

filled with PG-only based liquids containing similar nicotine concentrations (labelled and verified with a chromatography method)) but containing one of five different flavours, tobacco, piña colada, menthol, coffee or strawberry, we found that flavours have a significant and differential effect on in vitro toxicity. Most notably, menthol, coffee and strawberry-flavoured aerosols significantly reduced cell viability and metabolic activity compared to air controls $(\mathrm{p}<0.05$, figure 1 and table $3 \mathrm{~A}$, F). Interestingly, the effects of a strawberry-flavoured aerosol on metabolic activity and cell viability were not significantly different from those obtained with tobacco cigarettes. Piña colada-flavoured aerosol had an intermediate effect: it decreased metabolic activity as compared to air controls but had no significant effect on cell viability. In contrast to other flavours, aerosol generated from tobacco-flavoured liquid did not alter either viability or metabolic activity compared to air controls and was significantly less toxic than tobacco smoke $(\mathrm{p}>0.05)$.

When examining cytokine release, aerosols generated from coffee-flavoured and strawberry-flavoured liquids significantly increased cytokine levels compared to air controls (figure 1 and table $3 \mathrm{~A}, \mathrm{~F}$ ) or reference cigarettes (table $3 \mathrm{~A}, \mathrm{~F}$ ). Release of all tested cytokines except for IL- 6 was induced by the strawberryflavoured aerosol. Coffee-flavoured aerosol increased cytokine levels of IL-6, CXCL1 and CXCL2 compared to air controls. As the only difference among the products tested in this experiment was the flavour in liquids, we conclude that (1) flavours affect the in vitro toxicity profile of the product and (2) among all tested flavours, the product labelled strawberry was most toxic.

\section{Effects of nicotine concentration, carrier and battery output voltage on ENDS aerosol toxicity \\ Nicotine concentration}

Five nicotine concentrations were examined: $0,6,12,18$ and $24 \mathrm{mg} / \mathrm{mL}$. No significant differences $(\mathrm{p}<0.05)$ were observed between the various nicotine concentrations and the air control for metabolic activity and viability. Significant differences $(\mathrm{p}<0.05)$ were found among $0,6,12,18$ and $24 \mathrm{mg} / \mathrm{mL}$ concentrations and tobacco cigarette smoke for metabolic activity and/or viability. When compared against each other, we did not observe significant differences among the variable nicotine concentrations in either metabolic activity or viability (see online supplementary table S1). When examining the effect of nicotine 

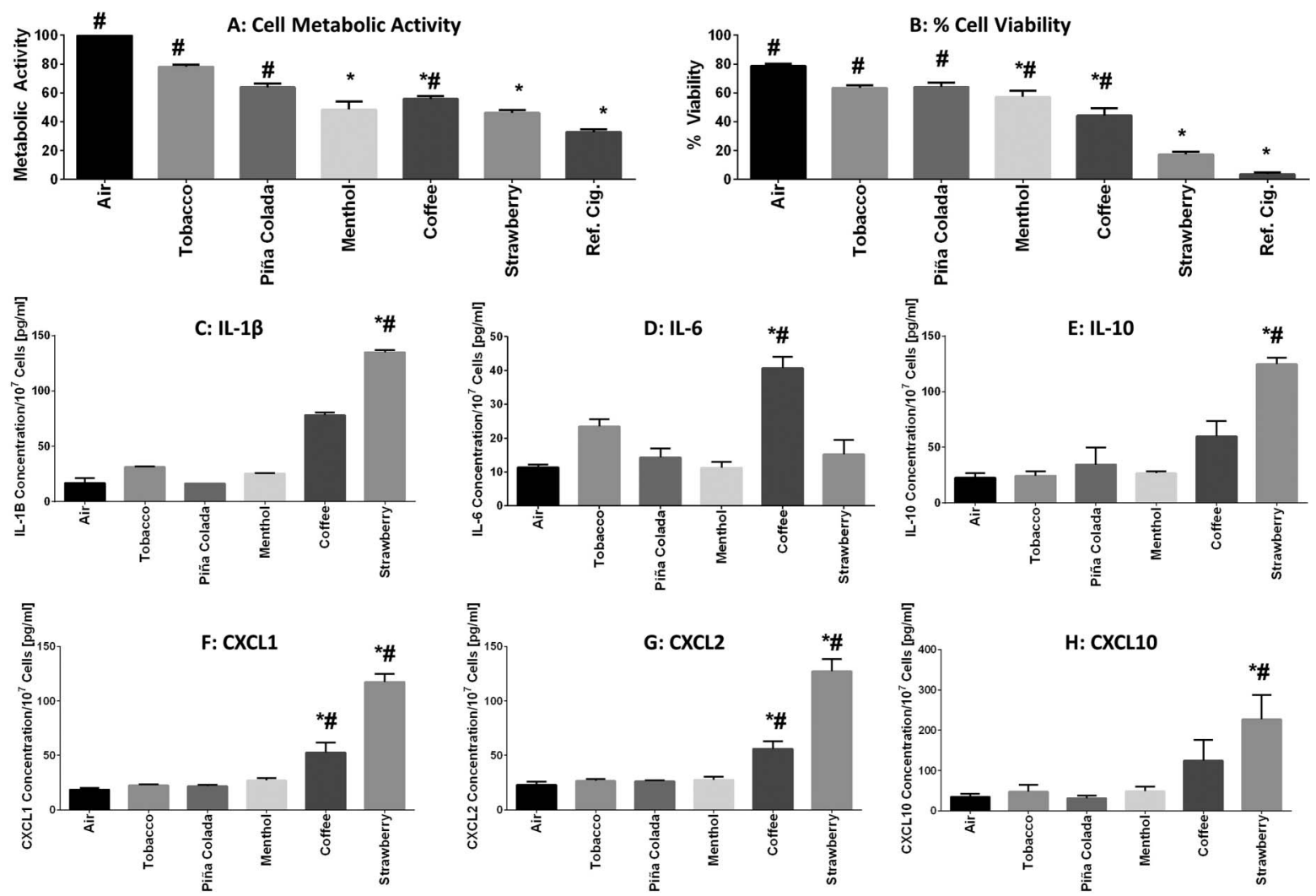

Figure 1 Comparison of cellular toxicity and levels of released inflammatory mediators (cytokines) from H292 bronchial epithelial cells directly exposed at the air-liquid interface to 55 puffs of flavoured ENDS aerosols. All flavoured ENDS aerosols were generated from an eGO tank system (Vision Spinner), with battery output voltage set to $3.3 \mathrm{~V}$ and refilled with PG-only solution with the same nicotine concentration (24 $\mathrm{mg} / \mathrm{mL})$. ENDS, electronic nicotine delivery systems; IL, interleukin; PG, propylene glycol

concentration on cytokine release, we found significant decreases in IL-1 $\beta$, CXCL1 and CXCL2 in response to exposure to $18 \mathrm{mg} / \mathrm{mL}$ of aerosol versus air controls (table $3 \mathrm{~A}$, D). IL-6 was significantly increased in response to $24 \mathrm{mg} / \mathrm{mL}$ of aerosol versus air control. IL-1 $\beta$ and CXCL2 levels were significantly decreased between $18 \mathrm{mg} / \mathrm{mL}$ of aerosol and the reference cigarette. Significant differences were observed among aerosols with variable nicotine concentrations for IL-1 $\beta$, IL-6, CXCL1 and CXCL2 (see online supplementary table S1).

\section{Nicotine carrier}

To study carrier effects, $\mathrm{H} 292$ cells were exposed at the ALI to aerosols generated from the same ENDS device (eGO tanks system set to $3.3 \mathrm{~V}$ ) filled with unflavoured liquids containing the same nicotine concentration of $24 \mathrm{mg} / \mathrm{mL}$ in (1) PG-only; (2) VG-only or (3) a 50/50 mixture of PG/VG (table $3 \mathrm{~A}, \mathrm{C}$ ). Compared to air controls, exposure of $\mathrm{H} 292$ cells to aerosols containing each of the tested carriers resulted in a significant decrease in cell viability $(p<0.05)$. However, all tested carriers were significantly less toxic to $\mathrm{H} 292$ cells than smoke from tobacco cigarettes (table $3 \mathrm{~A}, \mathrm{C}$ ). We found significant differences among the carriers themselves in their effects on cell metabolic activity (see online supplementary table S1), as the metabolic activity was significantly decreased in cells exposed to PG:VG and VG-only aerosols but not to PG-only as compared to air controls. When examining carrier effects on cytokine release, we identified a significant increase in all tested cytokines except CXCL1 and CXCL10 in cells exposed to PG-only as compared to air controls (table $3 \mathrm{~A}, \mathrm{C}$ ).

\section{Battery output voltage}

Three battery output voltage settings were tested: $3.3,4.0$ and $4.8 \mathrm{~V}$. Metabolic activity and cell viability were significantly decreased $(p<0.05)$ by the 4.0 and $4.8 \mathrm{~V}$ devices versus the air control (table $3 \mathrm{~A}, \mathrm{E})$. Aerosol generated with the device set to lower voltage $(3.3 \mathrm{~V})$ was not different than air and significantly less toxic than tobacco smoke $(p<0.05$; for metabolic activity and cell viability, table $3 \mathrm{~A}, \mathrm{E}$ ). We found significant differences among voltage settings in their effects on metabolic activity and cell viability (see online supplementary table S1). When examining the effect of battery output voltage on cytokine production, we found a significant increase in all tested cytokines as a result of the $4.8 \mathrm{~V}$ setting when compared to air controls.

\section{DISCUSSION}

This study used the physiologically relevant ALI system to systematically examine the cytotoxic and inflammatory effects of several ENDS variables including product type, nicotine concentration, carrier, product voltage and ENDS liquid flavour. Our results demonstrate that ENDS products significantly differ in their cellular toxicity to bronchial epithelial cells. This is an important finding to further understand the complexity of ENDS products. By systematically evaluating various product features, we were able to identify device power and flavouring additives as key components that significantly affect the potential toxicity of ENDS. This finding has important regulatory implications because both features of the ENDS products can be regulated and standardised. Our data indicate that ENDS users may reduce the potential harm from inhaling flavoured products 
by selecting flavours of lower toxicity profile and operating their device in lower power settings.

A novel finding of our study is that flavours used in ENDS liquids can have an acute cytotoxic effect on respiratory cells. We discovered that menthol, coffee and strawberry flavours had a significant impact on overall cytotoxicity of ENDS products. However, an important limitation of our study is that we did not look which of the flavouring compounds (as listed in table 2) caused this cytotoxicity and release of inflammatory mediators. Additionally, only one ENDS liquid product was tested for each flavour name (eg, strawberry). It remains to be determined whether other ENDS liquid products with the same flavour name that may contain an alternate flavour chemical composition yield a similar result. Further studies are needed to investigate the cytotoxic effect of single flavouring chemicals in ENDS liquids, combinations of these ingredients and the effects of alternate ENDS liquid products with the same flavour name. Our study indicates that testing toxicity of ENDS products should not be limited to individual flavouring chemicals since the ENDS liquids are complex mixtures, and other product features (eg, voltage) contribute to overall toxicity of ENDS aerosol. Finally, although we used the physiologically relevant ALI system, our study did not aim to estimate any harmful effects in ENDS users. Future in vivo studies are needed to confirm the applicability of our findings to human behaviours since exposure to flavoured ENDS aerosol among most vapers would be different than puffing protocol employed in our study.

Only a few studies have looked at the flavouring chemicals used in ENDS liquids. In GC/MS screening tests, we were able to tentatively identify several flavouring chemicals present in different products. When compared to the most comprehensive flavouring chemical scans to date, ${ }^{9}{ }^{10}$ we found five flavouring chemicals (3-methylcyclopentane-1,2-dione, menthol, limonene, benzyl alcohol and $\gamma$-decalactone) that were the same and six that were distinct from those previously reported. Screening the cytotoxicity of each flavouring chemical can be a very labour and time-consuming task, especially when one considers the number of possible interactions between different combinations of flavours with device power and carriers. There is an urgent need for time-effective and cost-effective methods to test flavoured ENDS products for their potential health effects.

Our study confirmed that increasing the device power by increasing battery output voltage resulted in significantly higher overall toxicity of ENDS aerosol. This finding is in line with a previous study, ${ }^{3}$ which found that increasing device voltage from 3.2 to $4.8 \mathrm{~V}$ resulted in an increased release of toxic carbonyl compounds. Cytokine levels were also found to be significantly elevated in cells exposed to the high-voltage products. These findings identify a complex interaction between product features and point towards some important challenges when testing the toxicity of different high-voltage or high-power devices. We found a significant increase in release of most cytokines in cells exposed to aerosols generated using PG-only carrier versus air controls. Interestingly, nicotine concentration did not have a significant cytotoxic effect on cells but induced release of the inflammatory cytokines as previously reported by others. $^{27}$

In summary, our data indicate that combinations of product, voltages and flavourings exist that are cytotoxic to airway epithelial cells. ENDS users should use the products with caution until more comprehensive studies are performed. Since our study focused on the acute effects of flavoured ENDS products, our observations require verification in chronic exposure models, more relevant to regular use of ENDS products.
What this paper adds

- The extent to which various product features and ingredients, including flavourings, impact electronic nicotine delivery systems (ENDS) safety and potential toxicity is currently not well defined.

- We tested different types and brands of flavoured ENDS on cell viability, cell metabolic activity and release of inflammatory cytokines in bronchial epithelial cells exposed in vitro directly to freshly generated ENDS aerosol.

- We found that various ENDS products differ with regard to their cellular toxicity and can cause different inflammatory reactions in cells directly exposed to aerosols.

- This study revealed that flavours significantly affect the in vitro toxicity profile of the ENDS products, and among all tested flavours, a commercially available fluid labelled strawberry was the most toxic.

Acknowledgements The authors thank Tatiana Shaurova, Erin McConnaghy and Kristina Powers for their assistance in running air-liquid interface experiments. The authors also thank Chelsea Koch for her assistance in running ELISA assays.

Contributors MLG contributed to the conception of the work. MLG, PAH, NJL and RIL contributed to data analysis and drafted the manuscript. NJL and RIL ran experiments. All authors approved the final version of the manuscript. MLG has full access to all study data and takes responsibility for the integrity of the data and accuracy of the data analysis.

Funding Research reported in this publication was supported by the National Institute on Drug Abuse of the National Institutes of Health under Award Number R01DA037446, the National Cancer Institute under Award Number P30 CA016056 and the Roswell Park Alliance Foundation.

Disclaimer The content is solely the responsibility of the authors and does not necessarily represent the official views of the National Institutes of Health.

Competing interests MLG reports grants from and served as an advisory board member to pharmaceutical companies that manufacture smoking cessation drugs. Other authors declare no conflict of interest.

Provenance and peer review Not commissioned; externally peer reviewed.

Data sharing statement Data could be made available to qualified researchers by request to the corresponding author.

\section{REFERENCES}

1 Grana R, Benowitz N, Glantz S. E-cigarettes a scientific review. Circulation 2014;129:1972-86

2 Goniewicz ML, Knysak J, Gawron M, et al. Levels of selected carcinogens and toxicants in vapour from electronic cigarettes. Tob Control 2014;23:133-9.

3 Kosmider L, Sobczak A, Prokopowicz A, et al. Cherry-flavoured electronic cigarettes expose users to the inhalation irritant, benzaldehyde. Thorax 2016;71:376-7.

4 McGill N. Research on e-cigarettes examining health effects: regulations due. Nations Health 2013:43:1-10.

5 Benowitz NL, Goniewicz ML. The regulatory challenge of electronic cigarettes. JAMA 2013;310:685-6.

6 CDC. Notes from the field: Electronic Cigarette Use Among Middle and High School Students—United States, 2011-2012. 2013. http://www.cdc.gov/mmwr/preview/ mmwrhtml/mm6235a6.htm (accessed 26 May 2016).

7 Wasowicz A, Feleszko W, Goniewicz ML. E-Cigarette use among children and young people: the need for regulation. Expert Rev Respir Med 2015;9:507-9.

8 Yingst JM, Veldheer $\mathrm{S}$, Hrabovsky $\mathrm{S}$, et al. Factors associated with electronic cigarette users' device preferences and transition from first generation to advanced generation devices. Nicotine Tob Res 2015;17:1242-6.

9 Hutzler $C$, Paschke M, Kruschinski S, et al. Chemical hazards present in liquids and vapors of electronic cigarettes. Arch Toxicol 2014;88:1295-308.

10 Tierney PA, Karpinski CD, Brown JE, et al. Flavour chemicals in electronic cigarette fluids. Tob Control 2016;25:e10-15.

11 Farsalinos KE, Romagna $\mathrm{G}$, Allifranchini $\mathrm{E}$, et al. Comparison of the cytotoxic potential of cigarette smoke and electronic cigarette vapour extract on cultured myocardial cells. Int J Environ Res Public Health 2013;10:5146-62.

12 Barrington-Trimis JL, Samet JM, McConnell R. Flavorings in electronic cigarettes. An unrecognized respiratory health hazard? JAMA 2014;312:2493-4. 
13 Lerner CA, Sundar IK, Yao H, et al. Vapors produced by electronic cigarettes and e-juices with flavorings induce toxicity, oxidative stress, and inflammatory response in lung epithelial cells and in mouse lung. PLoS One 2015;10:e0116732.

14 Misra M, Leverette RD, Cooper BT, et al. Comparative in vitro toxicity profile of electronic and tobacco cigarettes, smokeless tobacco and nicotine replacement therapy products: e-liquids, extracts and collected aerosols. Int I Environ Res Public Health 2014;11:11325-47.

15 Shen Y, Wolkowicz MJ, Kotova T, et al. Transcriptome sequencing reveals e-cigarette vapor and mainstream-smoke from tobacco cigarettes activate different gene expression profiles in human bronchial epithelial cells. Sci Rep 2016;6:23984

16 Scheffler S, Dieken H, Krischenowski O, et al. Evaluation of e-cigarette liquid vapor and mainstream cigarette smoke after direct exposure of primary human bronchial epithelial cells. Int J Environ Res Public Health 2015;12:3915-25.

17 Scheffler S, Dieken H, Krischenowski O, et al. Response to Polosa et al. Comments on Scheffler et al. Cytotoxic evaluation of e-liquid aerosol using different lung derived cell models. Int. J. Environ. Res. Public Health, 2015, 12, 12466-12474. Int J Environ Res Public Health 2016;13:pii: E109.

18 Hom S, Wang T, Chen L, et al. Electronic cigarettes modulate platelet inflammatory, adhesion, activation and aggregation responses. FASEB J 2016;30(Suppl 1):722.5.

19 Hwang JH, Alexander LC, Mathew D. Electronic cigarette inhalation promotes inflammatory cytokines within the airways and systemic inflammation in mice. Am J Respir Crit Care Med 2016;193:A4844.
20 Behar R, Davis B, Wang $Y$, et al. Identification of toxicants in cinnamon-flavored electronic cigarette refill fluids. Toxicol In Vitro 2014;28:198-208.

21 Hayes A, Bakand S. Inhalation toxicology. In: Luch A, ed. Molecular, clinical and environmental toxicology. Basel, Switzerland: Birkhäuser, 2010: 461-88.

22 Hayes AJ, Bakand S. Toxicological perspectives of inhaled therapeutics and nanoparticles. Expert Opin Drug Metab Toxicol 2014;10:933-47.

23 Aufderheide M. Direct exposure methods for testing native atmospheres. Exp Toxicol Pathol 2005;57(Suppl 1):213-26.

24 Goniewicz ML, Kuma T, Gawron M, et al. Nicotine levels in electronic cigarettes. Nicotine Tob Res 2013;15:158-66.

25 Goniewicz ML, Gupta R, Lee YH, et al. Nicotine levels in electronic cigarette refill solutions: a comparative analysis of products from the US, Korea, and Poland. Int J Drug Policy 2015;26:583-8.

26 Health Canada. Official Method T-115, Determination of "tar", nicotine and carbon monoxide in mainstream tobacco smoke, prepared by the Department of Health 1-7, dated 31 December 1999. http://www.hc-sc.gc.ca/hl-vs/alt_formats/hecs-sesc/ pdf/tobac-tabac/legislation/reg/indust/method/main-principal/nicotine/nicotine_e.pdf (accessed 20 May 2016).

27 Kalayciyan A, Orawa H, Fimmel S, et al. Nicotine and biochanin A, but not cigarette smoke, induce anti-inflammatory effects on keratinocytes and endothelial cells in patients with Behcet's disease. J Invest Dermatol 2007;127:81-9. 